\title{
VIRTUAL RECONSTRUCTION OF THE BIRTHPLACE OF REMBRANDT VAN RIJN: FROM HISTORICAL RESEARCH OVER 3D MODELING TOWARDS VIRTUAL PRESENTATION
}

\author{
P.J. De $\operatorname{Vos}^{1}$, M.J. De Rijk ${ }^{2}$ \\ ${ }^{1}$ Erfgoed Leiden en Omstreken, Boisotkade 2a, Leiden, The Netherlands - pj.de.vos@erfgoedleiden.nl \\ ${ }^{2}$ Mr. The Rich, Heimansbuurt 5, Alphen aan de Rijn, The Netherlands - mrtherich@gmail.com
}

Commission II, WG II/8

KEY WORDS: Rembrandt van Rijn, Virtual Reconstruction, Blender, VR, AR, Virtual Tour, Reliability Matrix

\begin{abstract}
:
2019 marks the 350th anniversary of the death of the famous seventeenth-century painter Rembrandt van Rijn. Rembrandt was born in 1606 in the city of Leiden, located in the Netherlands. Here he grew up, was educated and set up his early practice before moving to Amsterdam at age 31. He is the son of a miller's family, which lived and worked in the city at the dawn of the Dutch Golden Age a period in which Leiden transformed from a medieval city to an early modern metropolis. Although the historical city fabric of Leiden is well preserved, the birthplace of the famous painter, unfortunately, has been demolished. Also, the surroundings are unrecognizable today. For this reason, the tourism and marketing department of the city asked Erfgoed Leiden, the regional heritage department, to make a 3D virtual reconstruction of Rembrandt's birthplace and its surrounding. It resulted in a multi-disciplinary collaboration between archivists, building archaeologist, and a 3D artist. This paper reflects this cooperation from historical research over aspects of the 3D modeling pipeline to the final products of the reconstruction. Following a 'reliability' matrix, the data were categorized for their reliability after careful evaluation of their accuracy depending on the source.
\end{abstract}

\section{INTRODUCTION}

Over the last decade, 3D Virtual Models are often used to represent the reconstruction of (partly) existing and disappeared architectural heritage. Simultaneously, visual communications have increased tremendously. Society more and more expects to obtain information visually, also regarding cultural heritage. However in historical sciences, researchers are often reserved towards the use of reconstruction imagery. From the perspective of historical science, pictures are - although admired for their aesthetic merits - rarely treated as if they have as much to offer as the written word (Molyneaux, 2013). Moreover, within historical sciences pictures are often regarded as precarious.

On the one hand, this has to do with the traditional mistrust of Users towards Providers of contemporary technologies. It has been addressed before that the involvement of contemporary Digital Technologies in the domain of Cultural Heritage has increased the gap between Providers, i.e. those who master these techniques and are able to apply them and the Users, i.e. those scholars traditionally concerned with the Cultural Heritage (Georgopoulos, 2014). On the other hand, there is also the thought that in visualizing ideas, there would be no place for uncertainties and therefore for a scientific perspective. Indeed advertising, entertainment, and propaganda have us realized the extent of power that imagery can have to shape ideas. But just because of that, imagery can be interesting for historical sciences too.

Therefore, new challenges in visualizing research, lie within keeping up a fine balance between scientifical correctness and broader popular effectiveness. With this in mind, the project of the reconstruction of the birthplace of Rembrandt aimed to showcase the virtual reconstruction not only as a side product of written research, nor as a gimmick, but as a visual representation of historical research. The paper will discuss the wide scope of creating a virtual reconstruction, starting with (a.) historical research, over (b.) 3D modeling, to (c.) virtual presentation on different platforms. To conclude an evaluation of the project was made in the socalled 'Reliability Matrix'. But, firstly it is important to understand the context in which the reconstruction was made.

\section{TRADITION OF THE RECONSTRUCTION OF THE BIRTHPLACE OF REMBRANDT}

Rembrandt Harmensz van Rijn, (1606-1669) is considered one of the most important painters of the Dutch Golden Age, known for his compositions of light and shade and as an artist who favored an uncompromising realism (Van de Wetering, s.d.).

In the course of the nineteenth century, it was rediscovered that Rembrandt van Rijn was born in Leiden. Since then, the city and its inhabitants claim to have a profound influence on its glory and anchor the painter within the historical narrative of the city (De Vos et al. 2019). Leiden competes in this with the capital Amsterdam. Rembrandt left Leiden at the age of 31 to settle in the capital seeking his fortune. Rembrandt died at age 63 and was buried in the Westerkerk in Amsterdam.

Almost two centuries later, a statue of Rembrandt was placed at the Botermarkt to celebrate the glory of the painter. Soon it led to a renewed interest in his work and even caused a true Rembrandt cult. For that, the Botermarkt was renamed into the Rembrandtplein. In 1906, in remembrance of the painters $300^{\text {th }}$ birthday, the Rijksmuseum (national museum) built a new wing specially designed to showcase his most famous painting, the Night Watch. Today the museum hosts one of the biggest collections of Rembrandts. Furthermore, the city has the famous Rembrandt House, a museum dedicated to telling the story of the multi-faceted Rembrandt. The museum is located at Jodenbreestraat 4, where Rembrandt 
lived and worked for nearly twenty years (Van Melle, 2006). The house was purchased at the beginning of the $20^{\text {th }}$ century to be transformed into the leading museum it is today. Among others, these factors, together supported by strong city marketing strategies, have caused the fact that Amsterdam is regarded as being the Rembrandt city. Leiden stands in its shadow for a long time.

Already in 1906, also the city of Leiden went looking for the painter's physical roots, in search for its own "Rembrandt House". The search for his birthplace led to a horse stable in the fairly insignificant Weddesteeg. After a reporter from the local newspaper Leids Dagblad had visited it, he expressed his experiences as follows: "Being excited at first, I was left with only disappointment. An insignificant piece of wall, where there has been a chimney; nothing reminiscent of a mansion other than this silly, disguised in old age colors, piece of a stable wall" (Leidsch Dagblad, 1906). This disappointment of not having their own Rembrandt House that proves his historical presence and physically connects his roots to the city has never vanished. Because over the course of the last centuries the birthplace of Rembrandt and its surroundings have completely disappeared it is both for city dwellers as for many visitors hard to imagine (and therefore to believe) that the famous painter actually lived and worked in the city. Therefore, in 1963 a physical reconstruction of the house was made. The Leiden based architect M.P. Schutte created a $17^{\text {th }}$-century house that reflected not an actual situation, but the atmosphere, since "nobody knows how the house of Rembrandt looked like" (Nieuwe Leidsche Courant, 1963). The house was built as a two-story front-gabled building with a crow-stepped façade. Ten years later the reconstruction was demolished as it had to make place for a social housing project. In the 1980 s and in the early 2000 s ideas of reconstructing the birthplace of Rembrandt was proposed again. Even though funds had been made available, after consultation with the monuments and sites department of the city and the chair of architectural history from the University of Leiden, it was decided to abandon the plan. It was believed that due to a lack of sufficient historical sources, it would be impossible to arrive at a reliable reconstruction (De Vries, 2006).

\section{ARCHIVAL AND BUILDING ARCHAEOLOGICAL RESEARCH}

Almost 15 years later, Erfgoed Leiden en Omstreken, decided to take up this daunting challenge again. This time not making a physical reconstruction but a virtual. This task was even more demanding because not only the house itself needed to be reconstructed but the entire environment too. A big advantage in respect to 15 years ago is that since that time, the city was intensively researched by building archaeologists (De Vos, 2018). There crucial information at a detailed level was available on how was built, which techniques and which materials were used over the various periods. This information was key when coming to a reliable construction.

\subsection{Birthplace of Rembrandt van Rijn}

In building the reconstruction Erfgoed Leiden started off with archival research, in the first place to specifically locate the birthplace of the painter, a highly debated topic over the last 150 years. The new research led to a new perspective. It is not in the scope of this article to give an overview of the research (De Vos et al. 2019). Over-bluntly summarised the parents and grandparents of Rembrandt lived in the
Weddesteeg, on a large parcel located at the north of an alleyway. In different periods the father of Rembrandt acquired more property on the parcel, first in 1589, later around 1600 . At the time the painter was born in 1606 the house consisted of four different volumes, with three of them interconnected (fig. 2). A very useful source in the research was the so-called straetbouc (streetbook) of the late sixteenth century cartographer Van Dulmanhorst. This pre-cadastral map is most likely one of its kind in Europe. For every contemporary plot the measurements in Rhineland Rod at the street side and owner are indicated. On map nr. 13 the parcel of Rembrandt's step grandfather Cornelis Claesz van Berckel is indicated to the north of an alleyway, measuring about $19,46 \mathrm{~m}$ (fig. 1). The alleyway disappeared in the $20^{\text {th }}$ century, but is still visible on $19^{\text {th }}$-century cadastral maps.

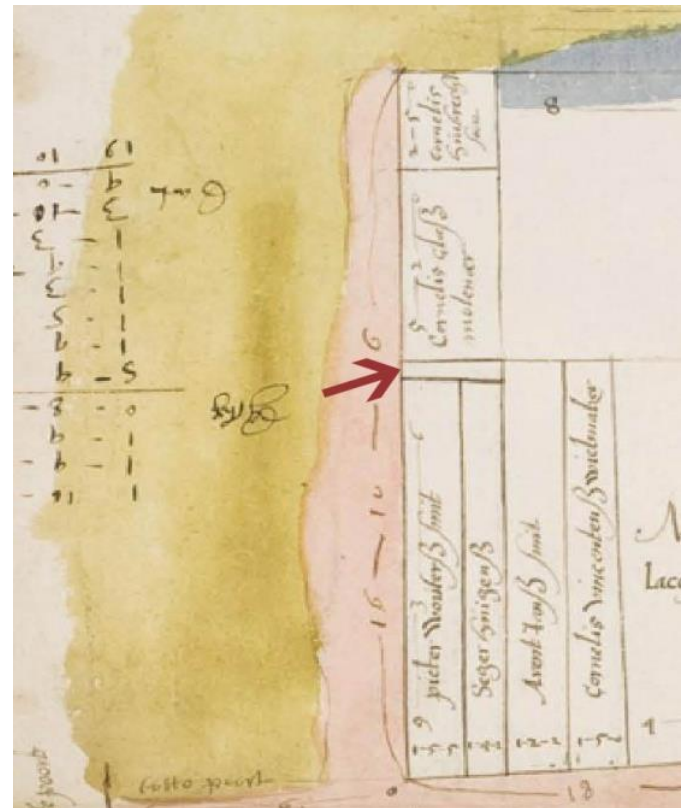

Figure 1. Detail, map 13 Van Dulmanhorst, in red the alleyway is indicated. Above the plot of Rembrandt's grandparents (ELO, SAII, 5153)

\subsection{Design of the house based on building history expertise}

After determining the exact location, the corresponding volumes were reconstructed. The width of the volumes can be derived from nineteenth-century cadastral information. Because the maps show the built and empty sections, these maps also provide information about the depth of the volumes. However, they do not offer a clear answer. Since the seventeenth century, the volumes were mostly likely extended to the back. To find the corresponding lines on the cadastral maps, first the orientation of the houses had to be determined. In medieval Leiden, the orientation is mostly limited to (a.) a transverse houses - a side-gabled building where the ridge runs parallel to the street and the volume is wider than it is deep; and (b.) a longitudinal deep house - a front-gabled building where the ridge is perpendicular to the street and the house is more deep than it is wide.

\subsection{Information from historical visual material}

An important source to determine the orientation of the volumes are different consecutive bird's-eye view maps from the late sixteenth and seventeenth century: i.e. the maps of 
Hans Liefrinck (circa 1538 - 1599) dated 1578; from Pieter Bast (1550 - 1605) dated 1600 and Joan Blaeu (1599 - 1673), dated 1633 and 1649. Also, the cityscape from 1592, by Jacob van Banchem was used. On the maps, an elongated building mass consisting of four volumes is shown north of the alleyway on the Weddesteeg. The volumes are shown as being transverse houses. One of the houses also has a crossed gable roof with a crow-stepped gable on the street side, a socalled Vlaamse gevel. Behind the houses on the alleyway are a few other volumes. The archival records indicate that at the time of his birth, Rembrandt's parents owned the two transverse houses and the court north of the alleyway, as well as the two volumes in the back.

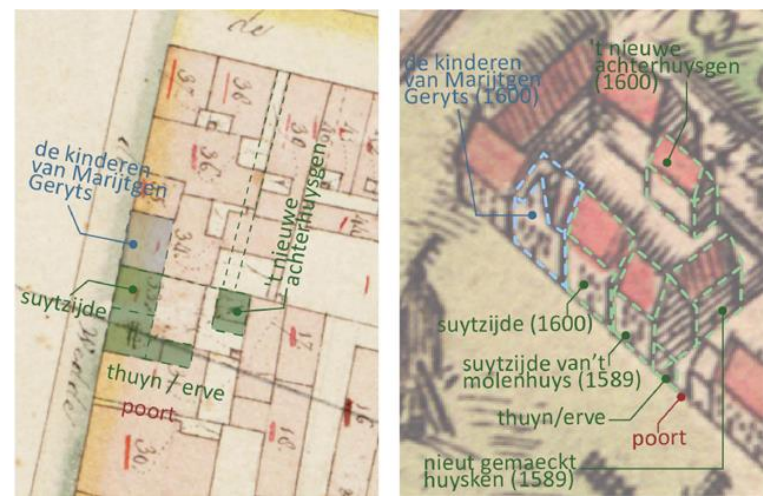

Figure 2. Rembrandt's birth house indicated in green. Left: the cadastral map of 1832 (RCE MIN08100B01); Right: the map of Bast from 1600 (ELO, PV329.1a.)

This image corresponds to previous building archaeological research, mainly carried out in the last 15 years. It is known that before 1600 the buildings in Leiden mainly had a ground floor and attic and that buildings with one floor were the exception, certainly on the alleys (Orsel, 2007a).

\subsection{Reconstruction of the exterior}

The design of the transversely placed houses with a ground floor and attic will correspond to the standard Leiden houses from that period (Orsel, 2007b). The standard houses from the time of Rembrandt's birth were built with crow-stepped gables or spout gables, but Dutch gables were also found. The reconstructed forms are based on images and measurements of examples found in Leiden. The overall building material at that time is an orange-red brick, often of size $18 / 19.5 \times 8.5 / 9 \times 4-5 \mathrm{~cm}$ and a 10-layer size of 49 $55 \mathrm{~cm}$, processed with lime mortar in a cross bond ending with a queen closer (Orsel, 2007c). The façade openings are usually equipped with timber cross windows or a door frame. The execution, materialization and detailing of the façade parts such as the window frames, window panes, hinges and locks, and gutters are based on historical-documented examples from Leiden.

In an early photograph from 1865 of the Kweekschool voor Zeevaart, a part of the roof of Rembrandt's birth house is depicted (fig. 3). Between the buildings a roof of a transverse house on the Weddesteeg is recognizable. Based on the location, it is the birth house of Rembrandt. The roof is laid with so-called old-Dutch roof tiles. Around 1600, the roofs of common Leiden houses are generally covered with these oldDutch tiles. These have been in use since the mid-sixteenth century. The roof pitch of houses in Leiden in that period is between 55 and 59 degrees (Orsel, 2009).

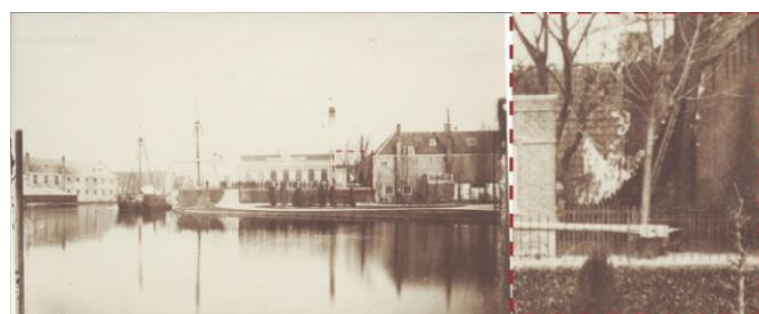

Figure 3. Detail of the newly built marine school in 1865 . Looking through the trees the roof of the birth house of Rembrandt is still visible (ELO, PV19590.2)

\subsection{Reconstruction of the interior}

For the exterior, it was possible to reconstruct the volume on the basis of bird-eye maps, cadastral and pre-cadastral maps. There are no such sources available for the interior of the house: no images, nor information such as estate inventories, were found in the archive. Nevertheless, by deducting the exterior parameters, the interior could be reconstructed to a certain degree (fig. 4). Historically, the location and main shape of a house dictate the location of the rooms logically and practically. The place of the cupboardbed in a house is logically determined by the darkest place. In Leiden, the cupboardbeds are often built in combination with a spiral staircase. The rooms are located on the facades due to maximum light.

The interior of the birth house will have corresponded with the general construction and finish of the common houses in Leiden. For all sorts of elements, the form, execution, dimensions and type of material are based on contemporary architectural examples documented in Leiden. Since the middle ages, the houses in Leiden have been built with brick walls and wooden floors. However by the time of Rembrandt's birth, a change in the building structure occurred. Before 1600 , houses were generally built with an unpainted oak timber frame construction in combination with a double floor consisting of beams and joists. Around 1600 it gradually changed into pine double floors supported by corbels. Because the birthplace of Rembrandt already existed at the end of the sixteenth century, it will have been built with the older construction method using a timber frame. The transverse shape of the house dictates that the beams are placed perpendicular to the front, in order to have the shortest span.

The further design is organized pragmatically and efficiently according to the needs of the user and has a long tradition and a logical evolution. The design of a house in Rembrandt's time is mainly determined by the social position and the wishes of the residents. The interior of the house was based on historical imagery and building archaeological findings that provide insight into the interior finish of a common Leiden house. That of Rembrandt's parents would not have looked very different. Inside walls were plastered and had a tiled plinth at the bottom. The floor will have been provided with baked tiles, possibly in different colors or in a pattern. For the simplest living comfort, a fireplace for heating and cooking was indispensable. The fireplace consists of a fireplace surmounted by a brick chimney fume hood on a wooden beam.

So, in spite of direct sources of the interior, based on deduction of the exterior parameters, as well as previous research and the use of historical paintings, it was possible to recreate a sense of how the general structure of the birth 
house of Rembrandt must have looked like at the beginning of the $17^{\text {th }}$ century - of course remaining an architectural impression. The project offered no room for the further decoration of the interior.

\section{VIRTUAL MODEL PIPELINE}

After the research was completed, the results could be combined in the virtual reconstruction. For 3D modeling, Blender (v. 2.79) was used, an open source equivalent of commercial software like Maya, 3D Studio Max or Cinema 4D. Texturing and painting were done using the commercial software Allegorithmic Substance Painter and Designer (v. 2018.3). The virtual model was rendered using Unreal Engine (v. 4.21) - a powerful freeware render engine.

\subsection{Exporting $x, y$ and $z$ information from GIS en CAD to Blender}

As mentioned, the entire surroundings of the Weddesteeg, the street where Rembrandt was born were demolished over the last centuries. To reconstruct the urban fabric, historical cartographic data was georeferenced in QGis (v. 3.4.2) to a vectorized cadastral map from 1832. Furthermore, all available (building) archaeological information of the area was put into the GIS-file to reconstruct the relative historical position of each object (houses, mills, earthworks, gates, bridges, etc.) in the reconstruction. From the GIS file, a 2D vector drawing (.dxf) was exported.

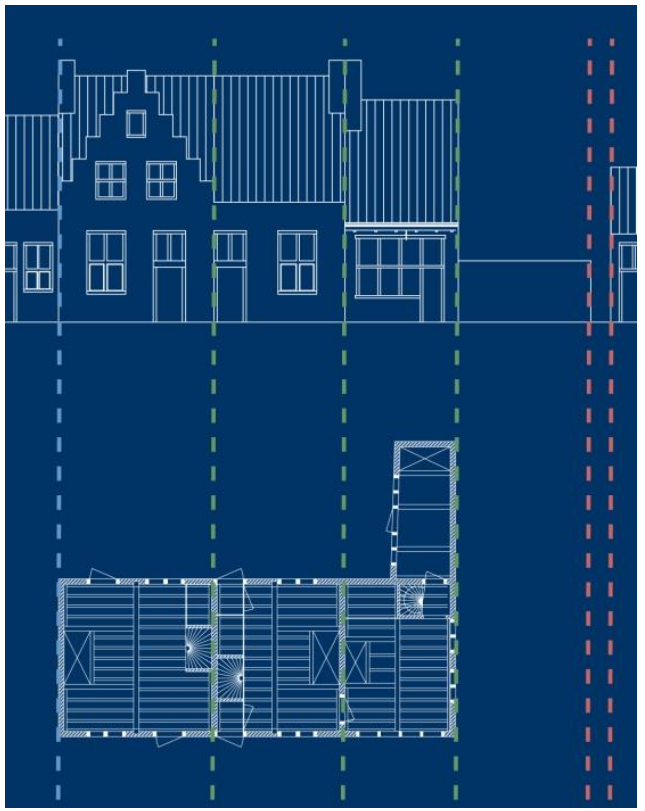

Figure 4. 2D CAD drawing of the elevation and plan of the reconstruction

\subsection{Combining $x, y$ and $z$ information in 2D CAD}

To obtain information about the Z-axis, historical drawings and pictures were interpreted and manipulated using photo rectification software (Perspective Rectifier) and CAD (AutoCAD 2017). In CAD, 2D drawings of the elevations, the plans and the sections, including historical details like windows, floor constructions, and decorative elements, were created. These drawings too were exported as a $2 \mathrm{D}$ vector drawing (.dxf). The vector drawings were imported into Blender to serve as a grid to make the outline of the 3D model. This led to a geometrically correct wireframe model. However virtual reconstruction also has a photorealistic component.

\subsection{Texturing masonry, paving and roof tiles}

For the creation of an authentic look, correct textures are vital. There are seamless textures for buildings available on the market that are often sufficient. In this particular project, such market textures were used for the more generic materials like oak timber. The downside of these textures is that they have an unsure source and because they are often based on photos, lack flexible options for creative control. Therefore custom textures were designed in Substance Designer for a hand full of textures that made up the main look of the birth house of Rembrandt.

Substance Designer was used in combination with Blender to create repeating textures for roof tiles, masonry and street paving. A procedural workflow combines shapes into patterns like a brick structure, and then various noise algorithms are strategically used to create variation, detail, and color. The final result is a texture set of multiple maps, a Colour map (albedo), a Normal map for relief, a Roughness map for reflectivity and an Ambient Occlusion map that holds information about detail shadows. These maps are then used in combination by the physically based rendering (PBR) engine (in Unreal Engine) to compose a realistic looking material.

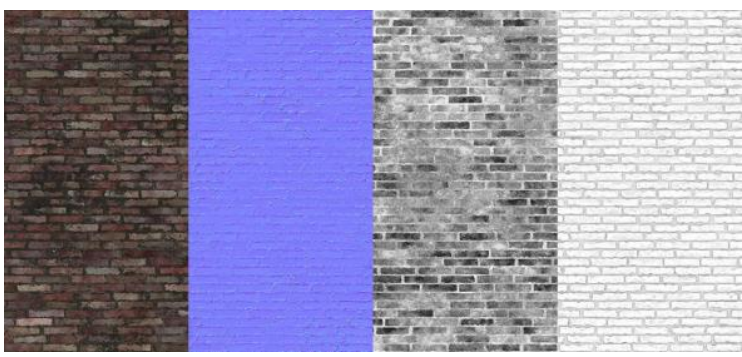

Figure 5. Material texture set of a clinker brick paving.

For the terracotta roof material, a little more work was needed because of the specific shape and relief of the roof tiles. First, a couple of variations of high-resolution roof tiles were modeled in Blender, based on 3D photogrammetric models (generated with Agisoft Photoscan) of real roof tiles dating from 1611. These were then arranged in a repeating pattern and baked into 2D textures that could be further processed in Substance Designer to add more detail like color variation, moss, and dirt. The relief information was extracted from the high-resolution arrangement into a grayscale texture map. This height map is used by the render engine to create a fake depth effect. Without this depth effect, the tiles would look flat and unconvincing, while trying to keep the geometric detail low.

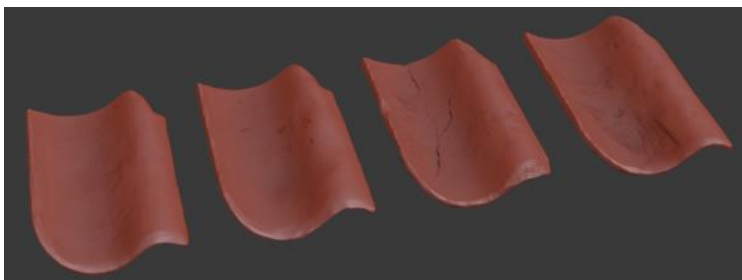

Figure 6. High-resolution models of roof tiles. (Blender)

Materials that were more generic were based upon photographs or market textures. To make these textures work 
in the PBR engine, other texture maps of the texture set needed to be generated from the base. In the case of photographs they needed to be made seamless, so they can be repeated as many times as needed without showing evident division lines. The program Bitmap2Material (by Allegorithmic) has a functionality that uses several algorithms to extract lighting information of the base texture, and generate from that the various detail and roughness maps, to create textures with a similar quality as the pre-described procedurally generated ones.

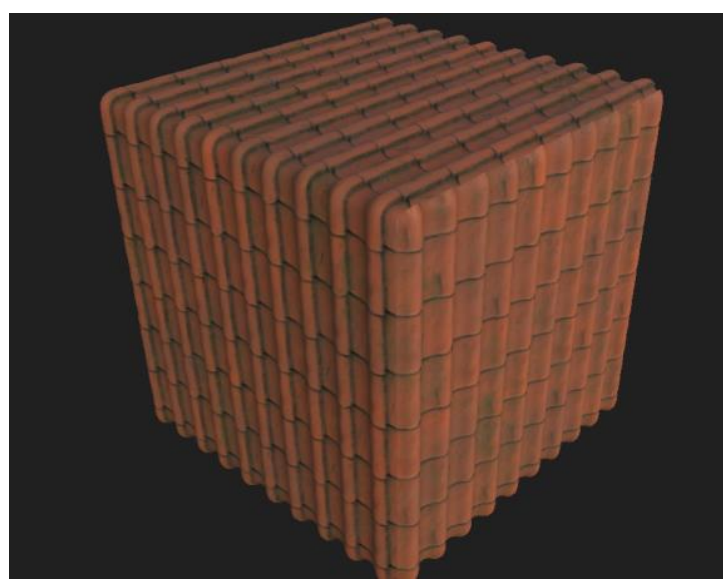

Figure 7. Final resulting roof material with the depth effect applied. (Substance Designer)

\subsection{Designing the cross-window frames}

Since the cross-windows make up a significant portion of the aesthetics of the 17th-century house, the designing of the frame needed extra attention in the project. The modeling pipeline for the windows shifted from the main approach. Careful examination of still existing window frames, old paintings, and research in construction methods were done to make sure the result was as authentically reconstructed as possible.

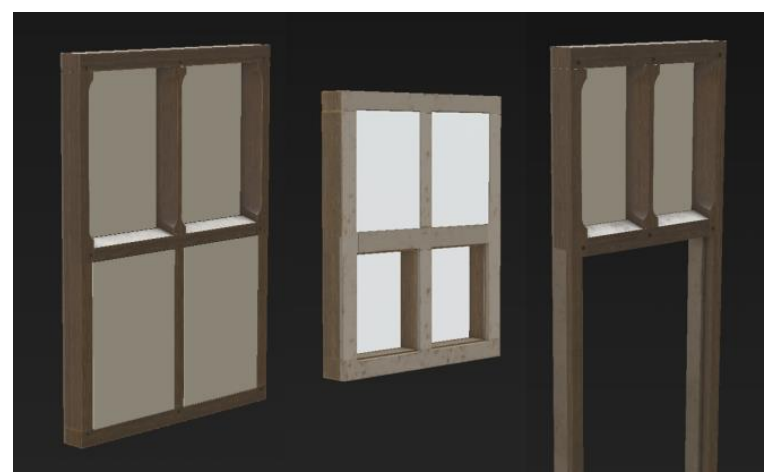

Figure 8. Various window and door frames with placeholder panels. (Substance Painter)

To prevent stretching of the frame model when using it for different sizes, a few different versions of the frames were made with different proportions, while using the same basic structure. The model was then deconstructed into its various construction parts to allow for finer control over the detail. The blank models of the wooden frame, the glass panes, the wooden shutters, and metal work were exported separately from Blender to Substance Painter to allow for material painting.
The separation of elements provided some complications with the procedural generation of dirt and dust, which were dependent on the relative position of the parts to each other. The settings allowed that dust would settle where the glass panes creates closed corners with the timber frame. However, without the panes in the export, the algorithm would not know where to apply dust. To circumvent this issue, some placeholder panels were put in place of the glass, but were not part of the actual model.

To make the glass panes look authentic, procedural methods were used to recreate the unevenness of old glass. The noise pattern was smoothed out and broken up per separate glass panel. This noise pattern was then saved within the Normal map, so that the render engine could use this to calculate the correct reflection and light breaking. The proximity of the lead frame allowed for the glass panels to be different to the edges, and also the dirt on the glass could be put in a realistic fashion. Variation in reflectance is what leads to realism, without the less reflective dirt, the glass would look less convincing for the eye.

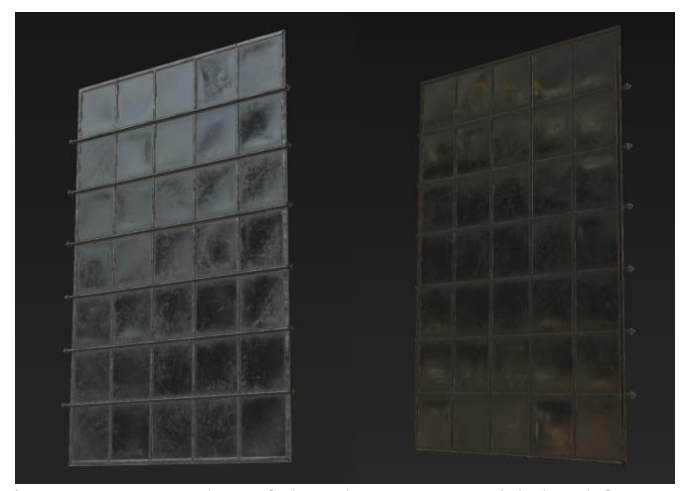

Figure 9. Examples of the glass panes with lead frames. (Substance Painter)

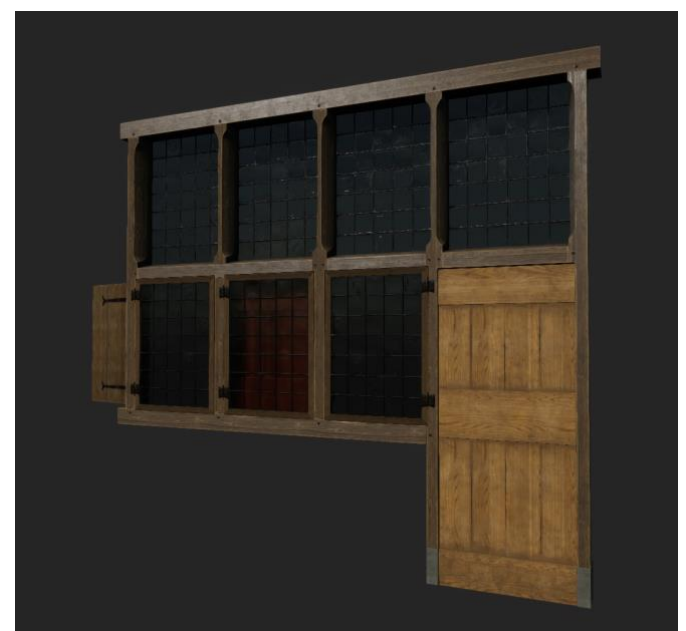

Figure 10. An assembled window frame (Unreal Engine)

The whole window, including frame and glass, was then imported into Unreal Engine 4, where the separate elements were combined together into one object. This allows the easy placement of the complete window while keeping the option open for variation in pose. E.g. a window that is half open. A little bit of code was needed to have all the elements work together. Because the metalwork (hinges) and the wooden frame were separate elements, the code synchronizes properties like rotation when a window or shutter opened. Care had to be taken with the placement of the windows into buildings. Because the size of the window apertures in the 
walls was dictated by the design of the gables, and so was varying house to house. A little amount of scaling and stretching was possible, as long as it stayed in the realm of believability. Otherwise, a differently proportioned window frame was needed.

\subsection{Real-time rendering using texture sets}

The rendering is done in real-time, in Unreal Engine, this means that every second a complete image is calculated 30 to 90 times. This method allows for direct feedback when creating the scene, and for direct interaction when observing it. This is a big advantage over the other method, ray tracing, at which a single image can take up to several hours to render, depending on the complexity of the scene. And while the ray tracing method allows for completely realistic results right off the bat, by simulating real light rays, real-time rendering has nowadays the capability of reaching this level of realism pretty well.

However, to reach this desired level, extensive optimization of the model is necessary. This is where texture sets come in. The general train of thought with texture sets is that you pack as much information necessary to reach a final image, into pre-calculated maps. These maps hold information about lighting, shadows, roughness, detail, calculated for every pixel. The processing unit then only has to do the final dynamic calculations between the current "camera" location, the lights and the objects, to get to a realistic result.

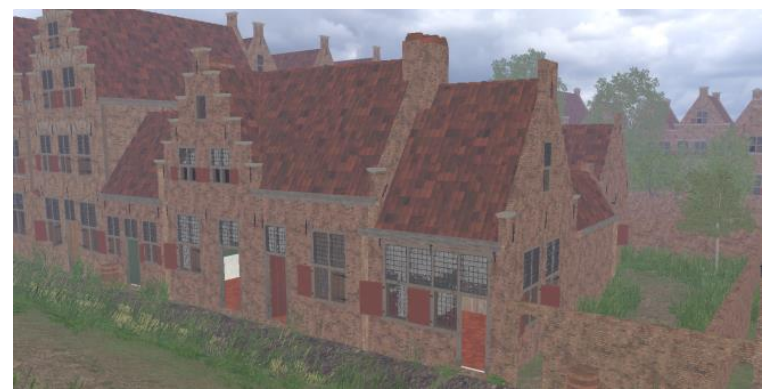

Figure 11. A scene with only color information and no lighting or effects. (Unreal Engine)

A vital part to the realism of a scene, something that comes automatically with ray tracing, is reflections. In the real world, light bounces around between objects until it loses its energy. This means that objects close to each other have an influence on each others appearance. The more reflective, the more precise this effect is.

Because there is no "real light" in the real-time world, this effect faked by pre-calculating reflection maps. In figure 13, the raw effect of these reflection maps can be seen. The little spheres indicate the "viewpoint" from where these reflections are observed. The roughness map in the material then determines how blurred this reflection should be at any given pixel. Which results in realistic variations between different types of materials (e.g. copper vs. timber)

These different calculations are then combined in a final pass to a complete image (fig. 14). This image can then be projected in real time on a screen, and react to inputs like moving the camera to a different location.

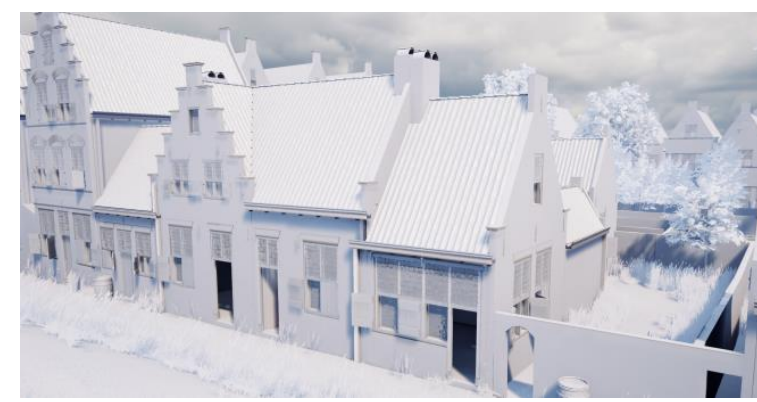

Figure 12. Shadow, light and detail calculations without color. (Unreal Engine)

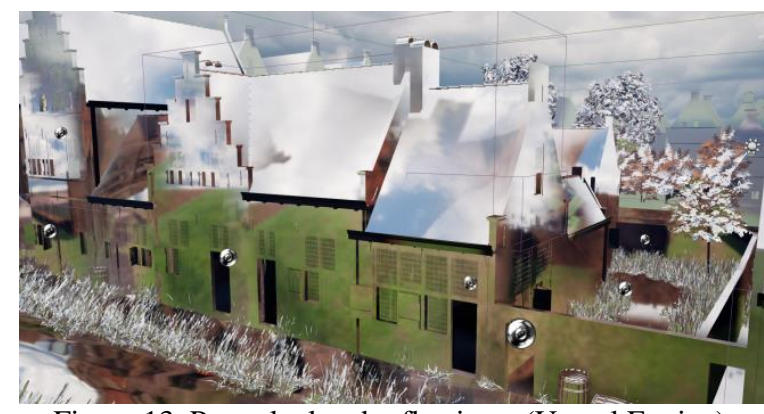

Figure 13. Pre-calculated reflections. (Unreal Engine)

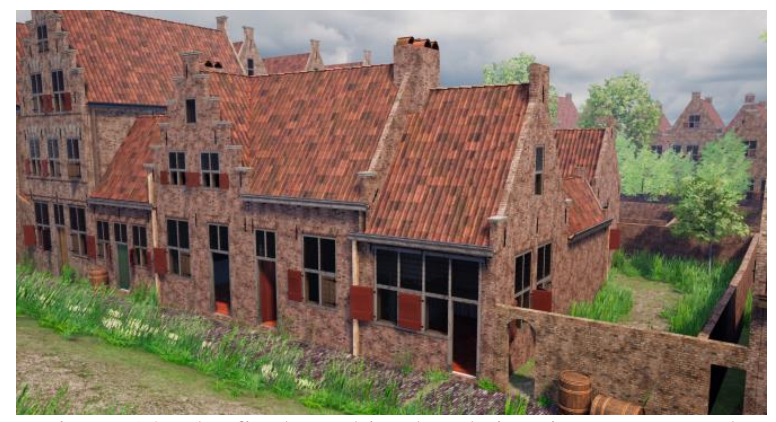

Figure 14. The final combined real-time image. (Unreal Engine)

Real-time rendering also allows for experience the environment in Virtual Reality. To achieve the effect of virtual reality, the previously described process is done twice, once for each eye. Simultaneously, the projection happens within a VR headset on two screens, allowing the brain to be tricked into a sense of depth.

Moving within the virtual scene is able because the VR headset tracks its location and gives this information back to the simulation. This cycle gives, together with tracked remote controllers in the hand, an interactive experience in a virtual world.

\section{ACCURACY VS. LIKELINESS}

In the previous, it became clear that the process of virtual reconstruction must be done very carefully in order to create the virtual model correctly both historically, geometrically and photorealistically. In order for virtual reconstruction not only to be a nice image but a scientific representation, the researcher needs to be transparent on all the decisions that were made during the project.

Over the course of the reconstruction, on a regular basis updates about the research of the Rembrandt house were published on the website of Erfgoed Leiden. In five articles both the research as the considerations made in relation to various source material were being published in order to be 
take away mistrust or skepticism from users (cfr. p. 1.). In order to not only provide the reconstruction as a fixed product for a wider audience, but also as a representation of historical science, this is an important step. In 2014, A. Georgopoulos, suggested for this exact reason to evaluate a virtual reconstruction in a 'Reliability Matrix'.

Within the matrix, the different sources that are used, are decreasingly graded from 10 to 1 , with one being the most reliable. "The measure does not have anything to do with the accuracy of surveying and photogrammetric measurements. Hence, the archaeological and architectural experts' opinion and assumptions are considered as most reliable" (Georgopoulos, 2014). The matrix was applied to the reconstruction of the birthplace of Rembrandt.

\begin{tabular}{|l|l|l|l|}
\hline SOURCES & REL. & IMP. & ASP. \\
\hline Written Documents & & & \\
\hline Transportation document of 1589 & 1 & 3 & EX, IN \\
\hline Inheritance document of 1600 & 1 & 3 & EX, IN \\
\hline Oud Belastingboek (1601-1642) & 1 & 8 & EX \\
\hline Register Vetus (1585-1601) & 1 & 8 & EX \\
\hline Bonboeken 1642-1811 & 3 & 8 & EX \\
\hline Historical imagery & & & \\
\hline Pre-cadastral map of Van Dulmanhorst \& Dou & 1 & 1 & ENV \\
\hline Birdeve view map from Bast 1600 & 3 & 1 & ENV, EX \\
\hline Birdexe view map from Bleau 1633 & 6 & 6 & ENV, EX \\
\hline Birdeve view map from Bleau 1649 & 6 & 6 & EX \\
\hline City scape from 1592 by Jacob van Banchem & 6 & 6 & EX \\
\hline Historic picture from 1865 & 1 & 7 & EX \\
\hline Cadastral map from 1832 & 2 & 2 & ENV, EX \\
\hline Cadastral map from 1879 & 2 & 2 & ENV, EX \\
\hline Building archaeological Assumptions & & & \\
\hline Deducting the interior & 5 & 1 & IN \\
\hline Gable design & 3 & 1 & EX \\
\hline Masonry work & 1 & 1 & EX \\
\hline Interpreting the volumes & 2 & 2 & ENV, EX \\
\hline Archaeological Surveying Measurements & 1 & 1 & ENV \\
\hline Orthorhotographic model & 1 & 4 & EX \\
\hline
\end{tabular}

Table 1. Reliability Matrix

When using the matrix as proposed by Georgopoulos, it was found out that the matrix itself is not enough differentiated. It should be extended by (a.) what is the impact of the source on (b.) the different aspects of the model. Various sources have a various impact on different aspects of the final model. In the case of the reconstruction of the Rembrandt house, the 3D model can roughly be divided into the urban environment (ENV), the exterior (EX) of the house, the interior of the house (INT). By extending the matrix with these parameters, the impact of the source to the final model becomes more clear.

The table above is not exhaustive. It is a simplified version of the entire matrix, but even the simple matrix gives a general impression on the usefulness of such a tool. Without reading through articles, one can understand the track of thought of the researchers as the matrix indicates the importance of certain sources over others.

\section{VIRTUAL PRESENTATION}

From the Virtual Model, a variety of outputs were generated: $360^{\circ}$ panorama images, stereoscopic panoramic images, walk-through video and still images of details.

The $360^{\circ}$ panorama images are used to design a virtual tour with interactive hotspots, built with the commercial software Pano2Vr (v. 5), which enables HTML5 output and functions through a plug-in within the main web platforms (Wordpress, Drupal, and Joomla). The virtual tour not only shows the $360^{\circ}$ panorama-imagery, but also links to 3D (photogrammetric) models, provide historic images, and additional text and reading, explaining the historical research conducted to build the reconstruction itself.

The $360^{\circ}$ images are also used in passive VR presentations, using the Oculus Go. The still images are put together in a continuous video loop, so spectators are guided passively trough the virtual area. At special occasions (e.g. Museum Night) an active VR-experience will be provided in which the digital model is being rendered real-time using the HTC Vive or the Oculus Quest. Furthermore, the model was downsampled to be used in an AR mobile application that was built by the tourism department of the city.

\section{CONCLUSIONS}

In 2019, Rembrandt's 350th anniversary is commemorated. This was the reason for Erfgoed Leiden to again pay attention to his birthplace in Leiden. The house and the environment where the world-famous painter lived and worked 400 years ago is unrecognizable in the current situation.

Combining historical and (building) archaeological research within a new perspective for the first time indicated the exact location of the birthplace and, moreover, has led to making a reliable reconstruction of the house and its surroundings. In order to visualize the historical research in all its details, it is evenly important to create the virtual model correctly geometrically and photorealistically. The geometries first were defined by making $2 \mathrm{D}$ vector drawings in both GIS and $\mathrm{CAD}$, after which they were 3D modeled in Blender. Substance Painter and Designer was used to provide textures. The final rendering was done in Unreal Engine.

The project leads to the creating of a reliable visualization of the newly carried out research and is attractive to a broader audience. Both the VR, AR and the panorama tour web application offer an accurate picture of the environment in Rembrandt's youth. In this way, Erfgoed Leiden hopes to conclude a century-old quest for Rembrandt's cradle and to contribute to a better experience and appreciation for the famous painter and its connection to Leiden.

\section{REFERENCES}

De Vos, P.J., 2019. Building archaeology in Leiden (NL): a practical approach. In: Professionalism in the Built Heritage Sector, pp. 27-36.

De Vos, P.J., Orsel, E.D., 2019. Het straatje van Rembrandt onderzoek en digitale reconstructie van het geboortehuis en zijn omgeving. Bulletin Koninklijke Nederlandse Oudheidkundige Bond, 118(4), [in press].

De Vries, D.J., 2006. In de ban van Rembrandt, huizen en herdenkingen. Bulletin Koninklijke Nederlandse Oudheidkundige Bond, 105(4), pp. 123-137.

Georgopoulos, A., 2014. 3D Virtual Reconstruction of Archaeological Monuments. Mediterranean Archaeology and Archaeometry, 14(4), pp. 155-164.

Leidsch Dagblad, 17 mei 1906. Wat van Rembrandts geboortehuis over is.

Molyneaux, B.L., 2013. The cultural life of images visual Museums. Journal of Cultural Heritage, 11, 452-458.

Nieuwe Leidsche Courant, 8 mei 1963. 
Orsel, E.D., 2007a. Zijn er nog 'veel' middeleeuwse huizen in Leiden?. In: Dwars door de stad, pp. 114-134.

Orsel, E.D., 2007b. 'Een fraij gesicht', het Leidse huis in de $17 \mathrm{de}$ eeuw, een poging tot typologiesering. Bulletin Koninklijke Nederlandse Oudheidkundige Bond, 106(1), pp. $11-25$.

Orsel, E.D., 2007c. Rijswijkers in Leiden. Bodemonderzoek in Leiden 20. M\&A Leiden, Leiden.

Orsel, E.D., 2010. The earliest development of roof construction in Leiden (NL). In: Proceedings of the Third International Congress on Construction History Cottbus 2009, pp. 1113-1120.

Van de Wetering, E., s.d. Rembrandt van Rijn, Encyclopcedia Britannica, britannica.com/biography/Rembrandt-van-Rijn

(30 June 2019).

Van Melle, M. 2006. De Rembrandtfeesten in 1906. Ons Amsterdam 5, https://www.onsamsterdam.nl/tijdschrift/ jaargang-2006/24-tijdschrift/tijdschrift-jaargang-2006/393nummer-5-mei-2006 (30 June 2019). 